\title{
СИНТЕЗ И СВОЙСТВА ПЛЕНОК СИСТЕМЫ CdS-ZnS, ЛЕГИРОВАННЫХ ИОНАМИ МЕДИ
}

\author{
(C) 2018 Т. В. Самофалова, В. Н. Семенов, А. Н. Нитута, О. В. Звягина, Е. Ю. Проскурина \\ Воронежский государственный университет, Университетская пл., 1, 394018 Воронеж, Россия \\ e-mail:TSamofalova@bk.ru
}

Поступила в редакцию 03.05.2018

\begin{abstract}
Аннотация. Представлены результаты исследования пленок системы CdS-ZnS, полученных методом пиролиза аэрозоля растворов координационных соединений $\left[\mathrm{M}\left(\mathrm{N}_{2} \mathrm{H}_{4} \mathrm{CS}\right)_{2} \mathrm{Br}_{2}\right](\mathrm{M}=$ $\mathrm{Cd}, \mathrm{Zn})$ при температуре $400{ }^{\circ} \mathrm{C}$ в присутствии ионов меди в концентрации $10^{-7}-10^{-3}$ ат. \%. Исследованы спектры поглощения в области края фундаментального поглощения, спектры фотолюминесценции и фазовый состав сульфидов. Найдены концентрационные зависимости оптической ширины запрещенной зоны $E_{g}(x)$ и межплоскостного расстояния $d(x)$ пленок системы CdS-ZnS. Выявлено, что введение примеси ионов меди в концентрации $10^{-7}-10^{-5}$ ат. \% увеличивает интенсивность фотолюминесценции.
\end{abstract}

Ключевые слова: метод пиролиза аэрозоля, тиомочевинные координационные соединения, пленки, сульфиды кадмия-цинка, оптическая ширина запрещенной зоны, спектры фотолюминесценции.

DOI: https://doi.org/10.17308/kcmf.2018.20/582

\section{ВВЕДЕНИЕ}

Пленки твердых растворов сульфидов кадмияцинка, легированные ионами меди, представляют значительный интерес для науки и микроэлектроники ввиду перспективности создания на их основе различных устройств: детекторов, светодиодов, электролюминесцентных экранов, лазеров, фотопреобразователей, устройств отображения информации и многих других приборов [1-4]. Поэтому актуальным является синтез пленок системы CdS$\mathrm{ZnS}$, активированных ионами меди, с контролируемой кристаллической структурой, оптическими и люминесцентными свойствами.

Ранее [5] были изучены люминесцентные свойства пленок $\mathrm{CdS}: \mathrm{Cu}$, осажденных пиролизом растворов тиомочевинных координационных соединений (TKC) $\left[\mathrm{Cd}\left(\mathrm{N}_{2} \mathrm{H}_{4} \mathrm{CS}\right)_{2} \mathrm{Cl}_{2}\right]$ при температуре $400{ }^{\circ} \mathrm{C}$, и выяснен механизм включения примеси в структуру сульфида. Проведенные в [6] исследования показали, что при введении ионов меди в концентрации $10^{-5}$ и $10^{-4}$ ат. \% люминесценция пленок $\mathrm{Cd}_{0.5} \mathrm{Zn}_{0.5} \mathrm{~S}$, осажденных из ТKC $\left[\mathrm{M}\left(\mathrm{N}_{2} \mathrm{H}_{4} \mathrm{CS}\right)_{2} \mathrm{Br}_{2}\right]$, усиливается в синей и зеленой областях спектра до 10 раз.

Целью данной работы является исследование влияния примеси ионов меди $\left(10^{-7}-10^{-3}\right.$ ат. \%) на кристаллическую структуру, оптические и люминесцентные свойства пленок системы $\mathrm{CdS}-\mathrm{ZnS}$, полученных из растворов ТКС $\left[\mathrm{M}\left(\mathrm{N}_{2} \mathrm{H}_{4} \mathrm{CS}\right)_{2} \mathrm{Br}_{2}\right]$.

\section{ЭКСПЕРИМЕНТАЛЬНАЯ ЧАСТЬ}

Пленки системы CdS-ZnS синтезировали методом пиролиза аэрозоля растворов координационных соединений $\left[\mathrm{Cd}\left(\mathrm{N}_{2} \mathrm{H}_{4} \mathrm{CS}\right)_{2} \mathrm{Br}_{2}\right]$ и $\left[\mathrm{Zn}\left(\mathrm{N}_{2} \mathrm{H}_{4} \mathrm{CS}\right)_{2} \mathrm{Br}_{2}\right]$ в присутствии ионов меди $\left(10^{-7}-10^{-3}\right.$ ат. \%). Для получения ТКС использовали бромиды металлов $\mathrm{CdBr}_{2} \cdot 4 \mathrm{H}_{2} \mathrm{O}$ и $\mathrm{ZnBr}_{2}$ марки Х.Ч. (0.05 моль/л) и тиомочевину $\mathrm{N}_{2} \mathrm{H}_{4} \mathrm{CS}$ марки ОС.Ч. (0.2 моль/л). В качестве активирующей примеси применяли бромид меди (+2). Проведенные ранее исследования [5] показали, что концентрация легирующей добавки в пленке соответствует ее концентрации в раствоpe. Концентрацию активатора в пленках пересчитывали в ат. \% $\mathrm{Cu}$.

В качестве подложек использовали кварцевые и ситалловые пластины. Температура синтеза составляла $400{ }^{\circ} \mathrm{C}$, время напыления образца 1-2 мин.

Определение кристаллической структуры и фазового состава пленок, полученных на кварцевых подложках, проводили методом рентгенофазового анализа (РФА) на дифрактометре ARL XTRA Ther- 
mo Scientific (излучение $\mathrm{Cu} K_{\alpha 1}$ ). Межплоскостные расстояния $d$, полученные из дифрактограмм, сравнивали со справочными из базы данных [7].

Оптическую ширину запрещенной зоны $E_{g}$ исследуемых сульфидов определяли из спектров поглощения по краю собственного поглощения из спектральной зависимости $D=f(h v)(D-$ оптическая плотность) в допущении прямых разрешенных переходов [8]. Спектры поглощения образцов, осажденных на кварце, снимали на спектрофотометрах CФ-2000-02 и Lambda 650 в диапазоне 190900 нм относительно чистой подложки.

Спектры фотолюминесценции (ФЛ) пленок, осажденных на ситалле, были сняты на автоматической спектральной установке в диапазоне 400-800 нм при комнатной температуре. Для возбуждения фотолюминесценции использовался светодиод HPL-H77V1BA-V2 с длиной волны $\lambda=380$ нм. Люминесцентное свечение пленки фокусировалось с помощью системы линз на входную щель монохроматора МДР-4. Спектр ФЛ образца регистрировался при помощи фотоумножителя ФЭУ R928P (Hamamatsu), работающего в режиме счета фотонов, и электронно-счетного частотомера ЧЗ-35А.

\section{РЕЗУЛЬТАТЫ И ИХ ОБСУЖДЕНИЕ}

Особенностью метода пиролиза аэрозоля растворов ТКС является то, что в зависимости от химической природы координационного прекурсора (вид лигандов, пространственное строение, образование водородных связей) возможно формирование сульфида металла той или иной полиморфной модификации. В галогенидных комплексах $\left[\mathrm{Cd}\left(\mathrm{N}_{2} \mathrm{H}_{4} \mathrm{CS}\right)_{2} \mathrm{X}_{2}\right](\mathrm{X}=\mathrm{Cl}, \mathrm{Br})$ имеются искаженные тетраэдрические фрагменты $\mathrm{CdS}_{2} \mathrm{X}_{2}$, из которых при термическом разрушении ТКС образуется наиболее устойчивая вюртцитная фаза сульфида $[9,10]$. При этом одним из основных типов дефектов в формирующихся пленках $\mathrm{Cd}_{x} \mathrm{Zn}_{1-x} \mathrm{~S}$ является атом галогена в анионной подрешетке $\left(\mathrm{Cl}_{\mathrm{S}}{ }^{\circ}, \mathrm{Br}_{\mathrm{s}}{ }^{\circ}\right)$.

Согласно результатам рентгенофазового анализа пленки системы $\mathrm{CdS}-\mathrm{ZnS}$ независимо от концентрации ионов меди кристаллизуются в структуре вюртцита (табл. 1). Межплоскостное расстояние $d$ в исследуемых образцах для различных плоскостей $h k l$ (например, $d_{002}$ ) при повышении в них доли сульфида цинка плавно уменьшается (рис. 1, табл. 1), что говорит об образовании неограниченных твердых растворов в рассматриваемой системе. При этом для пленок $\mathrm{Cd}_{x} \mathrm{Zn}_{1-x} \mathrm{~S}$, легированныХ ионами меди в разных концентрациях, наблюдается сходный характер изменения $d(x)$.

Анализ результатов РФА показал, что значения межплоскостных расстояний для легированных пленок одного и того же состава близки к значениям $d$ для нелегированных образцов. Так, для “чистых" пленок сульфида кадмия значение межплоскостного расстояния для плоскости (002) составляет 0.334 нм, для легированных ионами меди в концентрации от $10^{-7}$ до $10^{-3}$ ат. \% $-0.3340,0.3336$, $0.3345,0.3322$ и 0.3338 нм соответственно. Этот факт указывает на то, что введение активирующей примеси в данных концентрациях не оказывает сильного влияния на кристаллическую структуру синтезированных сульфидов $\mathrm{Cd}_{x} \mathrm{Zn}_{1-x} \mathrm{~S}$.

На дифрактограммах всех исследуемых образцов системы $\mathrm{CdS}-\mathrm{ZnS}$ наиболее интенсивными являются рефлексы, относящиеся к плоскости отражения (002), что позволяет говорить о преимущественной ориентации кристаллитов в этом направлении.

Спектры поглощения пленок системы CdS$\mathrm{ZnS}$, нелегированных и активированных ионами меди, имеют сходный вид. В качестве примера на

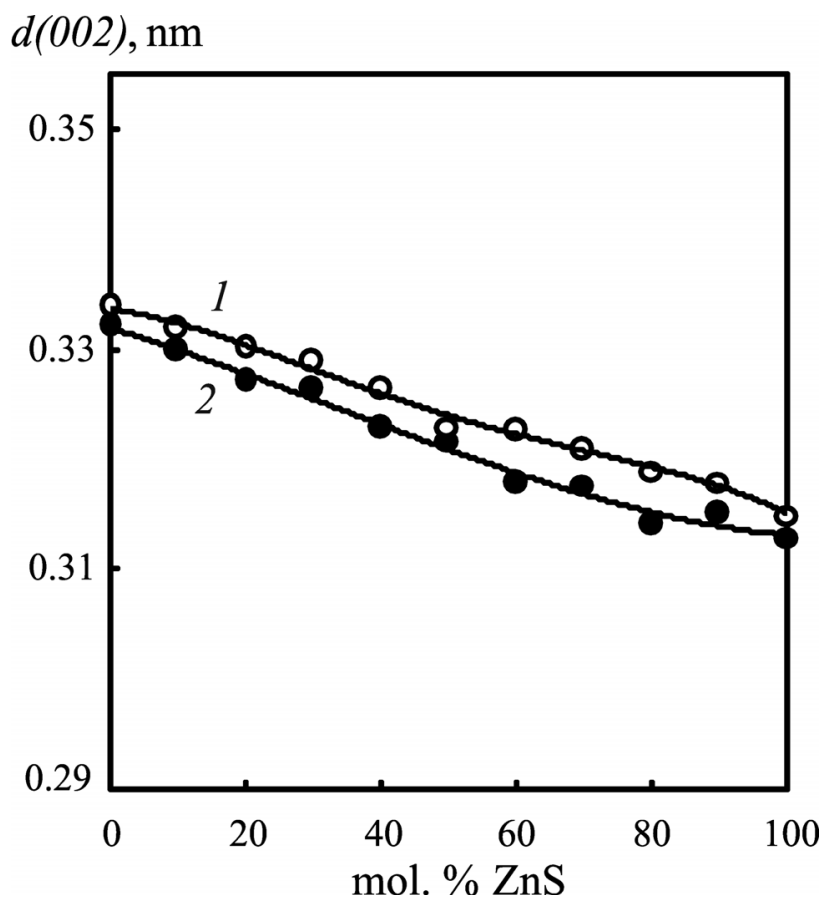

Рис. 1. Зависимость межплоскостного расстояния (002) от состава пленок системы CdS-ZnS, нелегированных (1) и легированных ионами меди в концентрации $10^{-4}$ ат. \% (2)

[Fig. 1. Dependence of the interplanar distances (002) on the composition of CdS-ZnS films, undoped (1) and doped by copper ions in a concentration of $10^{-4}$ at. \% (2)] 
Таблица 1. Межплоскостные расстояния в пленках системы $\mathrm{CdS}-\mathrm{ZnS}$, легированных ионами меди

[Table 1. Interplanar distances in the films of the $\mathrm{CdS}-\mathrm{ZnS}$ system doped by copper ions]

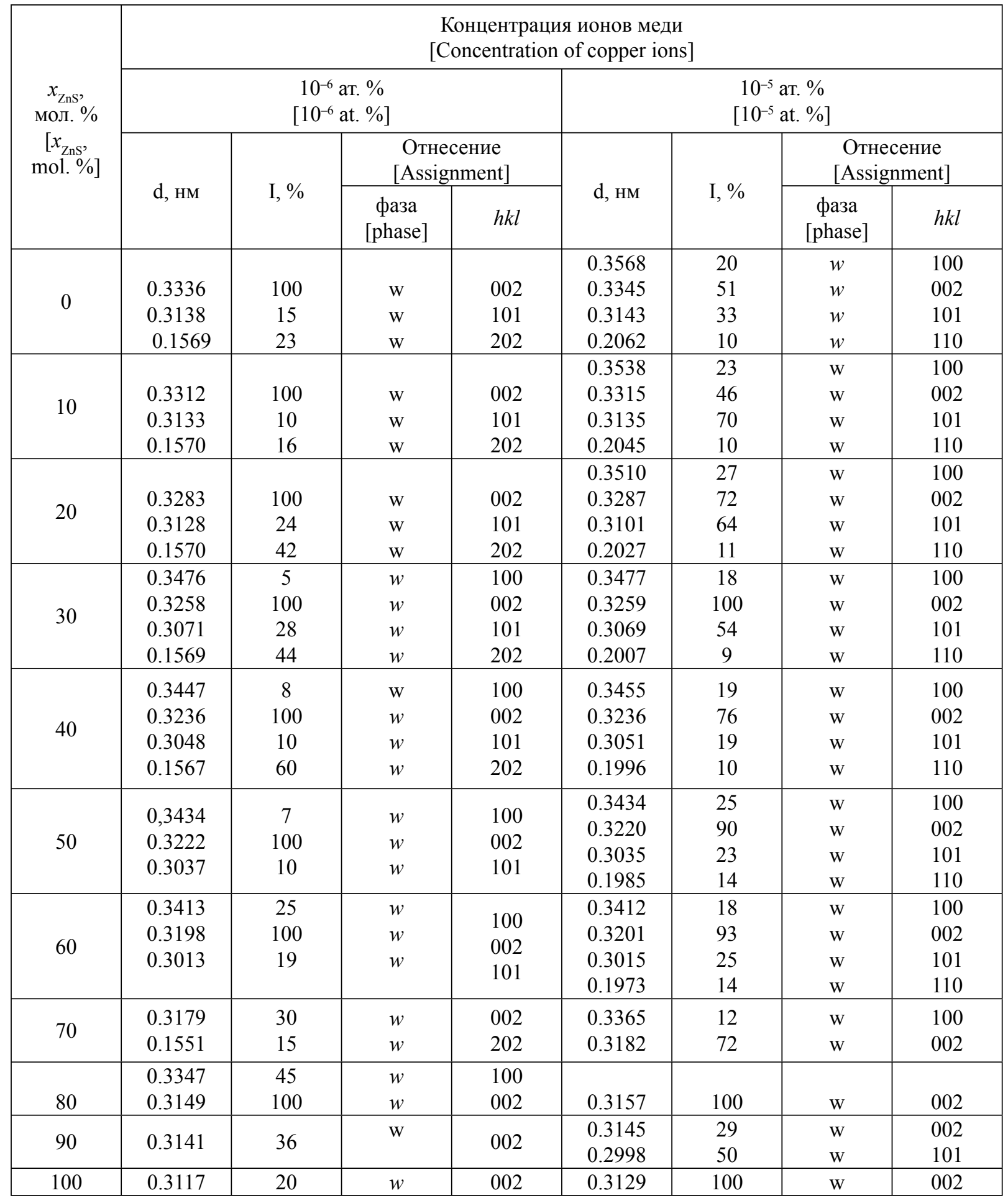

рис. 2 представлены спектры поглощения образцов, легированных ионами меди в концентрации $10^{-7}$ aт. $\%$.

Из рис. 2 видно, что с увеличением содержания сульфида цинка в осаждаемых образцах происходит смещение края поглощения в область более коротких длин волн. При этом оптическая ширина запрещенной зоны исследуемых сульфидов плавно и постепенно повышается (рис. 3), что указывает на формирование неограниченных твердых растворов в системе $\mathrm{CdS}-\mathrm{ZnS}$. Такой характер концентрационных зависимостей $E_{g}(x)$ наблюдается для всех 


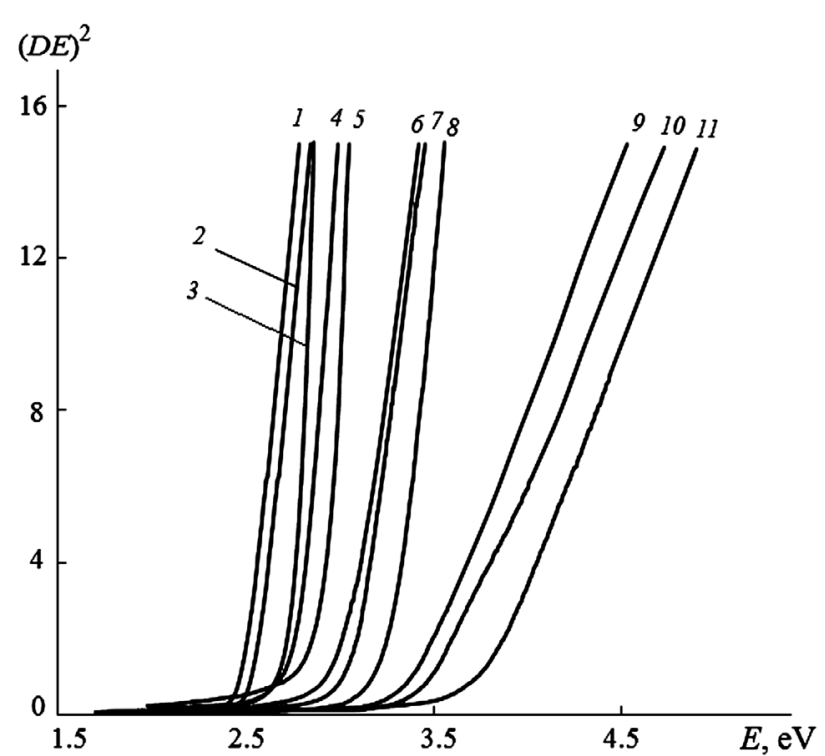

Рис. 2. Спектры поглощения пленок системы $\mathrm{CdS}-$ $\mathrm{ZnS}$, легированных ионами меди в концентрации $10^{-7}$ ат. \%: $1-0 ; 2-10 ; 3-20 ; 4-30 ; 5-40 ; 6-50 ; 7-60$; $8-70 ; 9-80 ; 10-90 ; 11-100$ мол. \% $\mathrm{ZnS}$

[Fig. 2. Absorption spectra of CdS-ZnS films doped by copper ions at a concentration of $10^{-7}$ at. \%: $1-0 ; 2-10$; $3-20 ; 4-30 ; 5-40 ; 6-50 ; 7-60 ; 8-70 ; 9-80 ; 10-$ 90; $11-100 \mathrm{~mol} . \% \mathrm{ZnS}]$

исследуемых пленок независимо от концентрации примеси ионов меди.

Следует отметить, что при повышении концентрации активирующей примеси оптическая ширина запрещенной зоны образцов изменяется незначительно (табл. 2). Разница в значениях $E_{g}$ для легированных пленок по сравнению с нелегированными составляет величину в пределах от 0.05 до $0.2 э \mathrm{~B}$. Это говорит о небольших изменениях дефектной структуры сульфидов $\mathrm{Cd}_{x} \mathrm{Zn}_{1-x} \mathrm{~S}$ при введении примеси ионов меди.

Спектры фотолюминесценции пленок $\mathrm{Cd} \mathrm{Zn}_{1-x} \mathrm{~S}$ чистых и полученных в присутствии ионов меди $\left(10^{-7}-10^{-4}\right.$ ат. \%) содержат широкую сложную полосу в области 400-800 нм. На рис. 4 представлены спектры люминесценции слоев

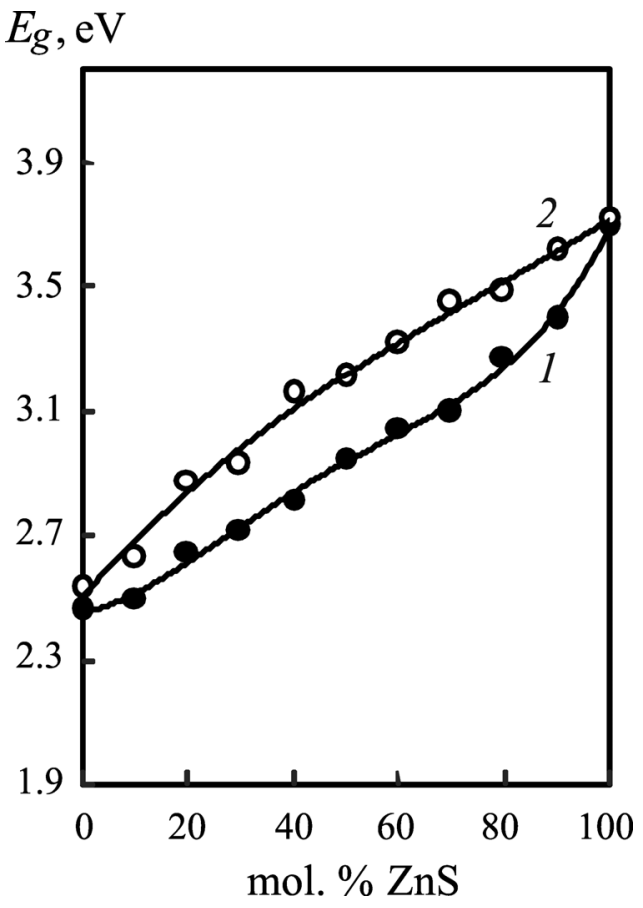

Рис. 3. Зависимости оптической ширины запрещенной зоны от состава пленок системы $\mathrm{CdS}-\mathrm{ZnS}$, легированных ионами меди в концентрациях $10^{-7}(1)$ и $10^{-4}(2)$ ат. $\%$

[Fig. 3. Dependencies of the optical band gap on the composition of the CdS-ZnS films doped by copper ions in concentrations of $10^{-7}(1)$ and $10^{-4}(2)$ at. \%]

$\mathrm{CdS}-\mathrm{ZnS}$, легированных ионами меди в концентрации $10^{-6}$ ат. \%.

Образцы, близкие по составу к сульфиду кадмия (от $\mathrm{CdS}$ до $\mathrm{Cd}_{0.5} \mathrm{Zn}_{0.5} \mathrm{~S}$ ), характеризуются наибольшей интенсивностью свечения. Это обусловлено повышением концентрации собственных дефектов, ответственных за центры излучательной рекомбинации, при увеличении содержания сульфида цинка в пленках при образовании твердых растворов замещения $\mathrm{Cd}_{x} \mathrm{Zn}_{1-x} \mathrm{~S}$. При повышении содержания сульфида цинка в образцах максимум полосы фотолюминесценции смещается в более коротковолновую область (рис. 4, 5). Это характерно как для “чистых”, так и легированных сульфидов $\mathrm{Cd}_{x} \mathrm{Zn}_{1-x} \mathrm{~S}$.

Таблица 2. Оптическая ширина запрещенной зоны пленок системы CdS-ZnS, легированных ионами меди

[Table 2. Optical band gap of the $\mathrm{CdS}-\mathrm{ZnS}$ films doped by copper ions]

\begin{tabular}{|c|c|c|c|c|c|c|}
\hline $\begin{array}{c}\text { Состав } \\
\text { [Sample composi- } \\
\text { tion] }\end{array}$ & \multicolumn{7}{|c|}{$\begin{array}{c}\text { Концентрация ионов меди, ат. \% } \\
\text { Concentration of copper ions, at. \%] }\end{array}$} \\
\cline { 2 - 7 } & 0 & $10^{-7}$ & $10^{-6}$ & $10^{-5}$ & $10^{-4}$ & $10^{-3}$ \\
\hline $\mathrm{CdS}$ & 2.52 & 2.46 & 2.46 & 2.47 & 2.53 & 2.55 \\
\hline $\mathrm{Cd}_{0.5} \mathrm{Zn}_{0.5} \mathrm{~S}$ & 3.14 & 2.95 & 3.15 & 3.21 & 3.21 & 3.15 \\
\hline $\mathrm{ZnS}$ & 3.69 & 3.70 & 3.84 & 3.81 & 3.73 & 3.83 \\
\hline
\end{tabular}




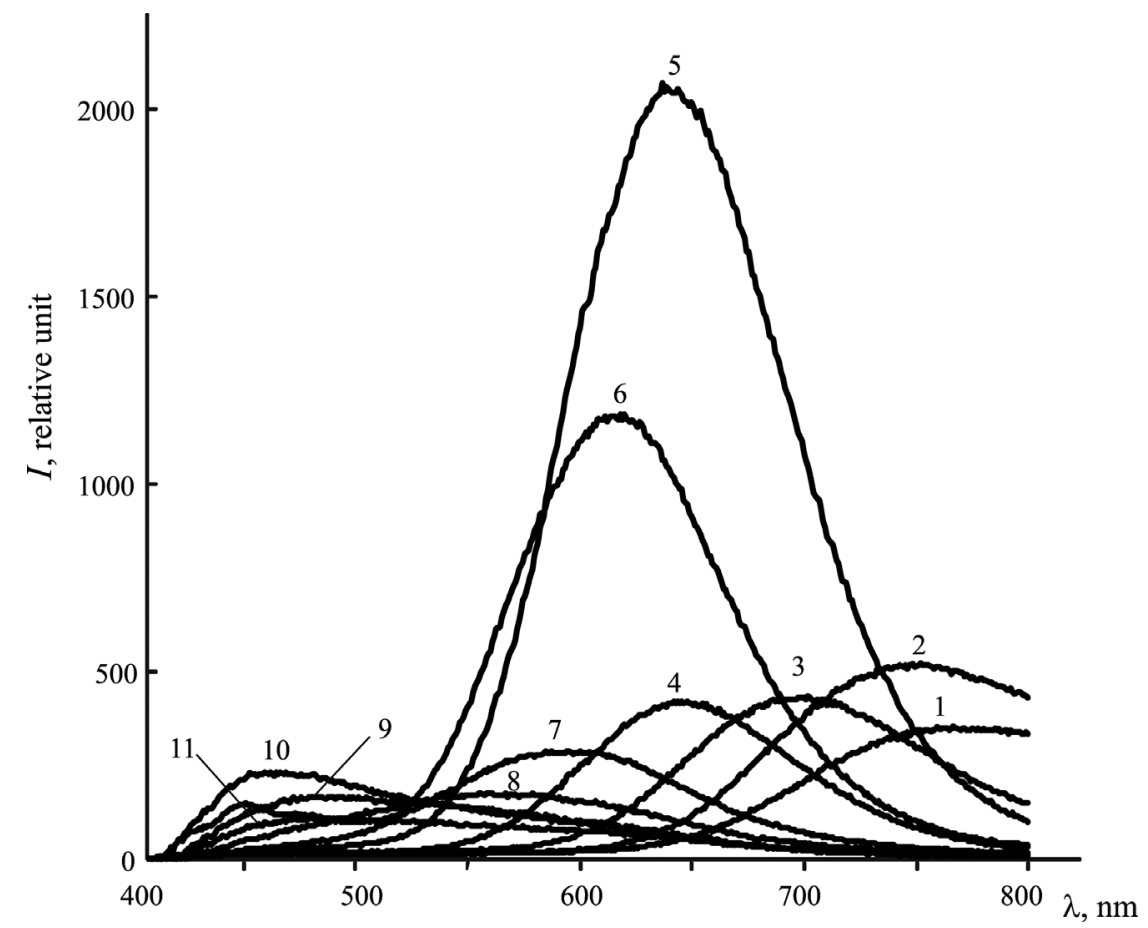

Рис. 4. Спектры фотолюминесценции пленок системы CdS-ZnS, легированных ионами меди в концентрации $10^{-6}$ ат. \%: 1 - 0; $2-10 ; 3-20 ; 4-30 ; 5-40 ; 6-50 ; 7-60 ; 8-70 ; 9-80 ; 10-90 ; 11-100$ мол. \% ZnS

[Fig. 4. Photoluminescence spectra of CdS-ZnS films doped by copper ions in a concentration of $10^{-6}$ at. \%: $1-0 ; 2-$ $10 ; 3-20 ; 4-30 ; 5-40 ; 6-50 ; 7-60 ; 8-70 ; 9-80 ; 10-90 ; 11-100$ mol. \% ZnS]

$\lambda_{\max }, \mathrm{nm}$

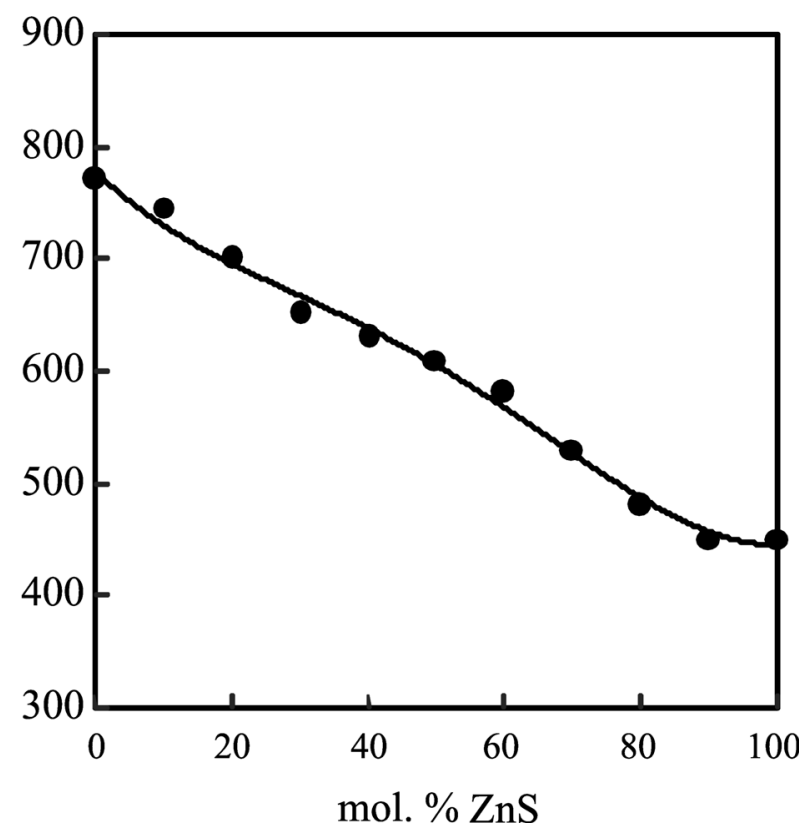

Рис. 5. Зависимость положения максимума полосы люминесценции от состава пленок системы $\mathrm{CdS}-\mathrm{ZnS}$, легированных ионами меди в концентрации $10^{-6}$ ат. \% [Fig. 5. Dependence of the position of the luminescence maximum on the composition of films of the CdS- $\mathrm{ZnS}$ system doped by copper ions in a concentration of $10^{-6}$ at. $\%$ ]
Каждая широкая полоса фотолюминесценции состоит из трех или четырех элементарных составляющих, что подробно рассмотрено в работе [6]. Структуру широких полос ФЛ можно объяснить следующим образом. Так как процесс осаждения образцов осуществляется на воздухе, образующиеся сульфиды содержат кислород, который совместно с легирующей примесью и собственными дефектами обуславливает люминесцентные свойства пиролитических пленок.

Являясь изоэлектронной примесью, кислород занимает места серы в узлах кристаллической решетки $\mathrm{O}_{\mathrm{S}}{ }^{\times}[11,12]$. Внедрение кислорода $\mathrm{O}_{\mathrm{S}}{ }^{\times}$, по всей видимости, приводит к смещению ближайшего атома кадмия (цинка), находящегося в центре тетраэдра, и образованию комплексов дефектов $\left[\mathrm{M}_{\mathrm{i}}^{*} \cdot \mathrm{V}_{\mathrm{M}}{ }^{\prime \prime}\right]^{\times},\left[\mathrm{M}_{\mathrm{i}} \cdot \cdot \mathrm{V}_{\mathrm{M}}{ }^{\prime \prime}\right]^{\prime},\left[\mathrm{M}_{\mathrm{i}}^{*} \cdot \mathrm{V}_{\mathrm{M}}{ }^{\prime}\right]^{\bullet}[11]$. Эти пары дефектов совместно с кислородом, занимающим места серы, образуют центры люминесценции в сульфидах цинка и кадмия. При легировании ионы меди замещают междоузельные ионы металла в обеих подрешетках с образованием центров $\left[\mathrm{O}_{\mathrm{S}}{ }^{\times} \cdot \mathrm{Cu}_{\mathrm{i}} \cdot \mathrm{V}_{\mathrm{M}}{ }^{\prime \prime}\right]^{\prime},\left[\mathrm{O}_{\mathrm{S}}{ }^{\times} \cdot \mathrm{Cu}_{\mathrm{i}}{ }^{*} \cdot \mathrm{V}_{\mathrm{M}}{ }^{\prime \prime}\right]^{\times},\left[\mathrm{O}_{\mathrm{S}}{ }^{\times} \cdot \mathrm{Cu}_{\mathrm{i}} \cdot \cdot \mathrm{V}_{\mathrm{M}}{ }^{\prime}\right]^{\cdot}$ $(\mathrm{M}=\mathrm{Cd}, \mathrm{Zn})$, которые участвуют в формировании широких полос люминесценции. Кроме того, свечение обуславливают комплексы дефектов $\left[\mathrm{V}_{\mathrm{M}} \mathrm{Br}_{\mathrm{S}}\right]^{\prime}$. 
По сравнению с нелегированными образцами системы CdS-ZnS для пленок, полученных в присутствии примеси ионов меди в концентрациях $10^{-7}, 10^{-6}$ и $10^{-5}$ ат. \%, наблюдается максимальная интенсивность фотолюминесценции (табл. 3), что обусловлено возрастанием количества центров свечения. При использовании концентрации активирующей примеси $10^{-6}$ ат. \% пленки $\mathrm{Cd}_{x} \mathrm{Zn}_{1-x} \mathrm{~S}$ характеризуются наибольшей интенсивностью фотолюминесценции. При более высокой концентрации активатора $\left(10^{-4}, 10^{-3}\right.$ ат. \%) интенсивность свечения уменьшается. Это может быть связано с тем, что при повышении концентрации активирующей примеси могут образовываться кластеры меди $\mathrm{Cu}_{\mathrm{n}}$, где $n=2,3, \ldots$ являющиеся центрами безызлучательной рекомбинации $[13,14]$.

\section{ЗАКЛЮЧЕНИЕ}

Методом пиролиза аэрозоля растворов тиомочевинных координационных соединений $\left[\mathrm{M}\left(\mathrm{N}_{2} \mathrm{H}_{4} \mathrm{CS}\right)_{2} \mathrm{Br}_{2}\right](\mathrm{M}=\mathrm{Cd}, \mathrm{Zn})$ при температуре $400{ }^{\circ} \mathrm{C}$ синтезированы пленки системы CdS-ZnS, легированные ионами меди в концентрации $10^{-7}$ $10^{-3}$ ат. \%. Установлено, что при используемых условиях осаждения в системе $\mathrm{CdS}-\mathrm{ZnS}$ происходит формирование неограниченных твердых растворов вюртцитной структуры.

Оптическая ширина запрещенной зоны пленок системы CdS- $\mathrm{ZnS}$ при увеличении содержания в них сульфида цинка изменяется от 2.46 до 3.84 эВ. Выявлено, что введение примеси ионов меди не оказывает сильного влияния на оптическую ширину запрещенной зоны. Установлено, что при использовании активирующей примеси в концентрации $10^{-7}-10^{-5}$ ат. \% наблюдается высокая интенсивность фотолюминесценции пленок $\mathrm{Cd}_{x} \mathrm{Zn}_{1-x} \mathrm{~S}$, максимальное значение - при концентрации ионов меди $10^{-6}$ ат. \%.

Работа выполнена при финансовой поддержке РФФИ в рамках научного проекта № 18-3301215 мол_а.

Исследования проведены с использованием оборудования Центра коллективного пользования Воронежского государственного университета. URL: http://ckp.vsu.ru.
Таблица 3. Максимальная интенсивность люминесценции $I_{\max }$ пленок $\mathrm{Cd}_{0.6} \mathrm{Zn}_{0.4} \mathrm{~S}$, легированных ионами меди

[Table 3. The maximum intensity of luminescence $I_{\max }$ of the films $\mathrm{Cd}_{0.6} \mathrm{Zn}_{0.4} \mathrm{~S}$ doped by copper ions]

\begin{tabular}{|c|c|}
\hline $\begin{array}{c}\text { Концентрация ионов меди, ат. \% } \\
\text { [Concentration of copper } \\
\text { ions, at. \%] }\end{array}$ & $\begin{array}{c}I_{\max }, \text { отн. ед. } \\
{\left[I_{\max }, \text { relative unit }\right]}\end{array}$ \\
\hline 0 & 645 \\
\hline $10^{-7}$ & 740 \\
\hline $10^{-6}$ & 2070 \\
\hline $10^{-5}$ & 1720 \\
\hline $10^{-4}$ & 582 \\
\hline
\end{tabular}

\section{СПИСОК ЛИТЕРАТУРЫ}

1. Голота А. Ф., Ищенко В. М., Тищенко С. М. // Вестник Ставропольского государственного университета, 2009, вып. 63, с. 107-113.

2. Самохвалов М. К. Электрические характеристики тонкопленочных электролюминесцентных индикаторов. Ульяновск, УлГТУ, 2006, 125 с.

3. Бланк Т. В., Гольдберг Ю. А. // ФТП, 2003, т. 37, вып. 9, с. 1025-1055.

4. Бобренко Ю. Н., Павелец С. Ю., Семикина Т. В., Шереметова Г. И., Ярошенко Н. В. // Оптоэлектроника и полупроводниковая техника: Сб. научн. тр., 2014, вып. 49, с. 69-74.

5. Семенов В. Н., Сушкова Т. П. Клюев В. Г., Кушнир М. А., Марков А. В. // Неорг. матер., 1993, т. 29, № 3, c. 323 .

6. Самофалова Т. В., Семенов В. Н., Клюев В. Г., Такмакова Е. В., Бездетко Ю. С. // Журн. прикл. спектроскопии, 2014, т. 81, № 1, с. 88-92.

7. Powder Diffraction File. Swarthmore: Joint Committee on Powder Diffraction Standards, 1996.

8. Уханов Ю. И. Оптические свойства полупроводников. М.: Наука, 1977, 367 с.

9. Семенов В. Н., Наумов А. В. // Вестник ВГУ. Сер. Химия. Биология, 2000, № 2, с. 50-55.

10. Наумов А. В., Самофалова Т. В., Семенов В. Н., Нечаев И. В. // Журн. неорг. химии, 2011, т. 56, № 4, c. 666-672.

11. Морозова Н. К., Каретников И. А., Блинов В. В., Гаврищук Е. М. // ФТП, 2001, т. 35, № 1, с. 25-33.

12. Морозова Н. К., Кузнецов В. А. Сульфид ичинка. Получение и оптические свойства. М.: Наука, 1987, $200 \mathrm{c}$.

13. Kluev V. G., Latyshev A. N. // J. Inf. Recording, 1996, vol. 23, p. 295.

14. Метелева Ю. В., Семенов В. Н., Клюев В. Г. и др. // Неорг. матер, 2001, т. 37, № 12, с. 1435-1438. 


\title{
SYNTHESIS AND PROPERTIES OF THE CDS-ZNS FILMS DOPED BY COPPER IONS
}

\author{
(C) 2018 T. V. Samofalova, V. N. Semenov, A. N. Nituta, O. V. Zvyagina, E. Yu. Proskurina \\ Voronezh State University, Universitetskaya pl., 1, 394018 Voronezh, Russia \\ e-mail: TSamofalova@bk.ru
}

Received 03.05.2018

\begin{abstract}
The main purpose of this work was to study the effect of the doping impurity of copper ions $\left(10^{-7}-10^{-3}\right.$ at. \%) on the crystal structure, optical and luminescent properties of CdS-ZnS films prepared by spray pyrolysis method from thiourea complex compounds $\left[\mathrm{M}\left(\mathrm{N}_{2} \mathrm{H}_{4} \mathrm{CS}\right)_{2} \mathrm{Br}_{2}\right](\mathrm{M}=\mathrm{Cd}$, $\mathrm{Zn}$ ) at a temperature of $400{ }^{\circ} \mathrm{C}$. X-ray diffractometry was used to determination of the crystal structure and phase composition of the obtained films. It is established that at the used conditions of the films deposition in the system $\mathrm{CdS}-\mathrm{ZnS}$ unbounded solid solutions of the wurtzite structure are formed. To determine the optical band gap, the absorption spectra of the films in the region of the self-absorption edge were studied. It was found that the optical band gap of the samples varies from 2.46 to $3.84 \mathrm{eV}$ with an increase in the content of zinc sulphide in them. It was found that the impurity of copper ions at used concentrations does not have a strong effect on the optical band gap. Photoluminescence spectra of $\mathrm{Cd}_{x} \mathrm{Zn}_{1-x} \mathrm{~S}$ films contain a wide complex band in the region of 400$800 \mathrm{~nm}$. The position of the photoluminescence maximum shifts to the short-wavelength region with an increase in the content of zinc sulphide in the samples. The highest intensity of luminescence is characteristic for $\mathrm{Cd}_{x} \mathrm{Zn}_{1-x} \mathrm{~S}$ films with a high content of cadmium sulphide. It is established that at the concentration of copper ions at $10^{-7}-10^{-5}$ at. \% the high photoluminescence intensity of $\mathrm{Cd}_{x} \mathrm{Zn}_{1-x} \mathrm{~S}$ films is observed, the maximum value is it at the dopant concentration of $10^{-6}$ at. $\%$.
\end{abstract}

Keywords: aerosol pyrolysis method, thiourea complex compounds, films, sulphides of cadmiumzinc, optical bandgap, photoluminescence spectra.

DOI: https://doi.org/10.17308/kcmf.2018.20/582

\section{ACKNOWLEDGMENTS}

The reported study was supported by grant the Russian Foundation for Basic Research according to the research project No 18-33-01215 mol_a.

The research results were obtained on the equipment of the Collective Use Center of Voronezh State University. URL: http://ckp.vsu.ru.

\section{REFERENCES}

1. Golota A. F., Ishhenko V. M., Tishhenko S. M. Vestnik Stavropol'skogo gosudarstvennogo universiteta [Vestnik Stavropol State University's], 2009, iss. 63, pp. 107-113. (in Russ.)

2. Samohvalov M. K. Jelektricheskie harakteristiki tonkoplenochnyh jelektroljuminescentny hindikatorov [Electrical Characteristics of Thin-Film Electroluminescent Indicators]. Ulyanovsk, UlGTU Publ., 2006, 125 p. (in Russ.)

3. Blank T. V., Gol'dberg Ju. A. Semiconductors, 2003, vol. 37, iss. 9, pp. 999-1030. DOI: 10.1134/1.1610111

4. Bobrenko Ju. N., Pavelec S. Ju., Semikina T. V., Sheremetova G. I., Jaroshenko N. V. Optojelektronika $i$ poluprovodnikovaja tehnika [Optoelectronics and Semiconductor Technology], 2014, iss. 49, pp. 69-74.

5. Semenov V. N., Sushkova T. P. Kljuev V. G., Kushnir M. A., Markov A. V. Neorganicheskie materialy [Inorg. Mater], 1993, vol. 29, no. 3, pp. 323-326. (in Russ.)

6. Samofalova T. V., Semenov V. N., Kljuev V. G., Takmakova E. V., Bezdetko Ju. S. Journal of Applied Spectroscopy, 2014, vol. 81, no. 1, pp. 87-91. DOI: 10.1007/ s10812-014-9891-z

7. Powder Diffraction File. Swarthmore: Joint Committee on Powder Diffraction Standards, 1996.

8. Ukhanov Yu. I. Optical Properties of Semiconductors. Moscow, Nauka Publ., 1977, 367 p. (in Russ.)

9. Semenov V. N., Naumov A. V. Proceedings of Voronezh State University. Series: Chemistry. Biology. Pharmacy, 2000, no. 2, pp. 50-55. (in Russ.)

10. Naumov A. V., Samofalova T. V., Semenov V. N., Nechaev I. V. Russian Journal of Inorganic Chemistry, 2011, vol. 56, no. 4, pp. 621-627. DOI: 10.1134/S0036023611 040218

11. Morozova N. K., Karetnikov I. A., Blinov V. V., Gavrishhuk E. M. Semiconductors, 2001, vol. 35, iss 1, pp. 24-32. DOI: 10.1134/1.1340285 
12. Morozova N. K., Kuznecov V. A. Zinc Sulphide. Obtaining and Optical Properties. Moscow, Nauka Publ., 1987, 200 p. (in Russ.)

13. Kluev V. G., Latyshev A. N. J. Inf. Recording, 1996, vol. 23, p. 295.
14. Meteleva Yu. V., Semenov V. N., Klyuev V. G., Smerek S. A. Inorganic Materials, 2001, vol. 37, no. 12. pp. 1224-1227.
Самофалова Татьяна Владимировна - к. х. н., ассистент кафедры общей и неорганической химии, Воронежский государственный университет; тел. +7(473) 2208610, e-mail: TSamofalova@bk.ru

Семенов Виктор Николаевич - д. х. н., профессор, заведующий кафедрой общей и неорганической химии, Воронежский государственный университет; тел. +7(473) 2208610, e-mail: office@ chem.vsu.ru

Нитута Асият Насрулаховна - аспирант кафедры общей и неорганической химии, Воронежский государственный университет; тел. +7(473) 2208610, e-mail: asiyat.nituta@yandex.ru

Звягина Ольга Владимировна - магистрант химического факультета, Воронежский государственный университет; e-mail: orebenok@mail.ru

Проскурина Елена Юрьевна - к. х. н., ассистент кафедры общей и неорганической химии, Воронежский государственный университет; тел. +7(473) 2208610, e-mail: helko7@yandex.ru
Tatyana V. Samofalova - Cand. Sci. (Chem.), Assistant Lecturer, Department of General and Inorganic Chemistry, Voronezh State University; tel.: +7(473) 2208610, e-mail: TSamofalova@bk.ru

Victor N. Semenov - Dr. Sci. (Chem.), Full Professor, Head of the Department of General and Inorganic Chemistry, Voronezh State University; tel.: +7(473) 2208610, e-mail: office@chem.vsu.ru

Asiyat N. Nituta - postgraduate student, Department of General and Inorganic Chemistry, Voronezh State University; tel.: +7(473) 2208610, e-mail: asiyat.nituta@yandex.ru

Olga V. Zvyagina - master student, Department of General and Inorganic Chemistry, Voronezh State University; e-mail: orebenok@mail.ru

Elena Yu. Proskurina - Cand. Sci. (Chem.), Assistant Lecturer, Department of General and Inorganic Chemistry, Voronezh State University; tel.: +7(473) 2208610, e-mail: helko7@yandex.ru 